\title{
Erratum
}

\section{Population parameters incorporated into genome-wide tagSNP selection - ERRATUM}

\author{
A. P. Silesian and J. Szyda \\ (First published online 19 October 2015)
}

doi:10.1017/S175173111300044X, published by Cambridge University Press, 25 March 2013

In the article by Silesian and Szyda (2013), the authors inadvertently neglected to include that the study was carried out within the framework of the MASinBULL (currently Genomika Polska) project. The authors apologise for this omission and confusion caused.

\section{Reference}

Silesian AP and Szyda J 2013. Population parameters incorporated into genome-wide tagSNP selection. Animal 7, 1227-1230. 